gate mistletoe without their intervention. All that is necessary for success is to introduce very carefully a few seeds into a shallow notch made in the bark of an appletree, and bind it round delicately with bass or damp moss. The apple-tree is the surest stock, for, though it is found elsewhere, yet there is a certain constancy in the apparent caprice shown by the mistletoe in the selection of its victims. It occurs frequently on the poplar, hawthorn, willow, and lime; never on the beech, holly, cherry, and walnut; rarely on the chestnut and pear, and only in some few known instances upon the oak. Probably the rarity of its occurrence on the oak contributed to the reverence with which, under those circumstances, it was regarded by our British ancestors. To them a mistletoe-oak was a tree beloved of heaven-a symbol of life and death-a promise of renewal of strength to the leafless monarch of the glade. When the New Year's festival came round, the Arch-Druid, clothed in white, mounted the tree, and cut the mistletoe with a golden sickle. As it fell into the white cloth held to receive it, two white bulls also fell to the ground as sacrificial victims; and the prayer went forth from the Druid's lips that God would prosper his gift, and make it a charm potent against poison, and a certain cure for sterility.

It is curious to notice how this traditional connection between the mistletoe and New Year's Day, and a belief in its virtues, have survived among the natives of the Western Marclies. In Herefordshire, at any rate, no mistletoe enters into the Christmas decorations of house and church; but on New Year's Eve, many of the old farmers and cottagers still go forth to cut their bough, and hang it up with all solemnity as the clock strikes twelve. Nor are the medical properties of the mistletoe forgotten by them. Before turnips were extensively cultivated, old Tusser's precept was regularly followed:-

$$
\begin{aligned}
& \text { If snowe doe continue, sheepe hardly that fare } \\
& \text { Crave mistle and ivie for them for to spare. }
\end{aligned}
$$

And even now faith in the virtues of the plant (which is in fact a gentle tonic) may here and there be found. "What is mistletoe good for ?" asked Dr. Bull of a Herefordshire rustic. "That do depend on what tree it comes from," was the reply. "It be a very fine thing for fits. My father had the 'leptic fits for many years, but nothing never did him no good like mistletoe from the haw, mixed with wood-laurel, and he took nothing else. They do tell me that mistletoe from the maiden ash be a fine thing for convulsives. I know when you get it from the mawpell it's good for animals. It's capital for sheep as don't go on well at lambing-time, and for cows too. That as comes from the apple-tree and poplins is the best to hang up in the house on New Year's Day for good luck through the year; but a many people use any that comes first. A piece of mistletoe from the haw-from the haw, sir-chopped in pieces and given to a cow after calving, will do her more good nor any drench you can give her." Sir Thomas Browne mentions the practice of thus administering it among his "Vulgar Errors," but at least it is one not likely to be attended with evil consequences.

The reason of the exclusion of mistletoe from church decoration may be gathered from what has already been said, and to this we musti add, that its appearance there might be likely to suggest something more ardent than "the kiss of peace." But in hall and cottage alike the mistletoe reigns supreme at this season, and in London and other great towns the artisan spends a small portion of his Christmas wages in the purchase of a few sprigs wherewith to decorate his house and bring good luck to its inmates. From Herefordshire and Worcestershire between 200 and 300 tons of mistletoe are annually exported, and during the present week nearly every train from the West Midland district bears with it a truck-load of branches, fraught with we know not what romance, and bright with berries wherein is contained the destiny of the coming year.

\section{THE MIDNIGHT SKY*}

SURELY if ever there were an Astronomy made easy, here it is: if ever there were a sensible Christmas present for a boy, here it is. In fact, it is impossible to commend Mr. Dunkin or the Religious Tract Society too highly for the work which they have jointly produced. It is an honest, scientifically sound, beautiful book, with appeals both to the eye and the mind: one in which the magnificence of the heavens and the deep teachings of modern science go hand in hand, until at last the unscientific reader will certainly find himself deeply interested in the discussion of questions, and the followingout of reasonings, which but a few short years ago were generally supposed to furnish day-dreams to solitary astronomers, who dwelt in towers far removed from the ken of their fellows, and still further removed from their pursuits and interests.

That such a state of things is past and gone, and that the glories of the firmament are now eagerly revelled in by thousands, ay, and even tens of thousands, is in the main owing to the publication of such books as the "Midnight Sky," and the many handy series of star-maps which Mr. Proctor and others have produced.

The book contains carefully drawn views of the midnight sky; at London, looking north and south, for every night in the year. These views are accompanied in each case by an index-map giving the names of the principal stars. In order that these maps may be utilised at any other hour than midnight, Mr. Dunkin has provided the observer with a tabular statement which gives at one view the hour and month when each diagram of the series is available for comparison with the sky. The descriptions appended to these maps are clearly written in a style which will not be found beyond the comprehension of the least scientific reader. Mr: Dunkin next gives a description of the midnight sky of the southern hemisphere, in the months of February, May, August, and November. Following these articles and star-maps, we find an interesting account of the constellations, general notes on the milky way, the magnitudes, scintillation and colour of the stars, analysis of solar and stellar light, the observatories in the southern hemisphere, and remarks on nebulae and clusters. Notes on the sun, moon, and earth, the major and the minor planets, succeed, and the work is concluded by a full account of meteors and shooting stars, a copious index serving to give increased usefulness to the book.

The Religious Tract Society has done wisely in entrusting the writing of these familiar notes to an astronomer of such high ability as Mr. Dunkin. Not only have we at once a guarantee of correctness in the facts themselves, but there is insured that freedon of style which only an intimate acquaintance with a subject can give, and, in the case of such a far-reaching and intricate science as astronomy, this consideration is of high importance-witness the flabby books written by incompetent men.

In the latter part of the rork, which forms a sort of treatise on astronomy, Mr. Dunkin dwells among other matters on solar eclipses, and gives several very interesting anec. dotes connected with them which we do not remember to have seen in print before. In the notes on the sun we detect a little hasty writing, which the author will do well to correct in subsequent editions. In the first place the hydrogen is the sun's chromosphere, is not in a state of combustion but of incandescence; and M. Le Verrier gets credit for an assertion he made in 1860 , which, had $\mathrm{Mr}$. Dunkin printed the context, would be evidently absurd, according to our present knowledge. Father Secchi is credited too with having proved satisfactorily the hollow

* "The Midnight Sky." Familiar Notes on the Stars and Planets. By Edwin Dunkin, F.R.A.S., Royal Observatory, Greenwich. 'Thirty-two Starmaps and other Iilustrations, pp. 326. Religiou's Tract Society. 
structure of sun spots, the fact being that Father Secchi has only clumsily followed in the footsteps of others, and has contradicted himself in the process. We might have expected also a little notice of the bearing of the recent work on the theories of the constitution of the sun and with the timid, feeble, faith-lacking tone of many of the more modern orthodox.

Besides the star-maps and key-maps, specimens of which we give, there are excellent telescopic views of the star-cluster in Perseus, the moon, comets, \&c., and drawings of Sir

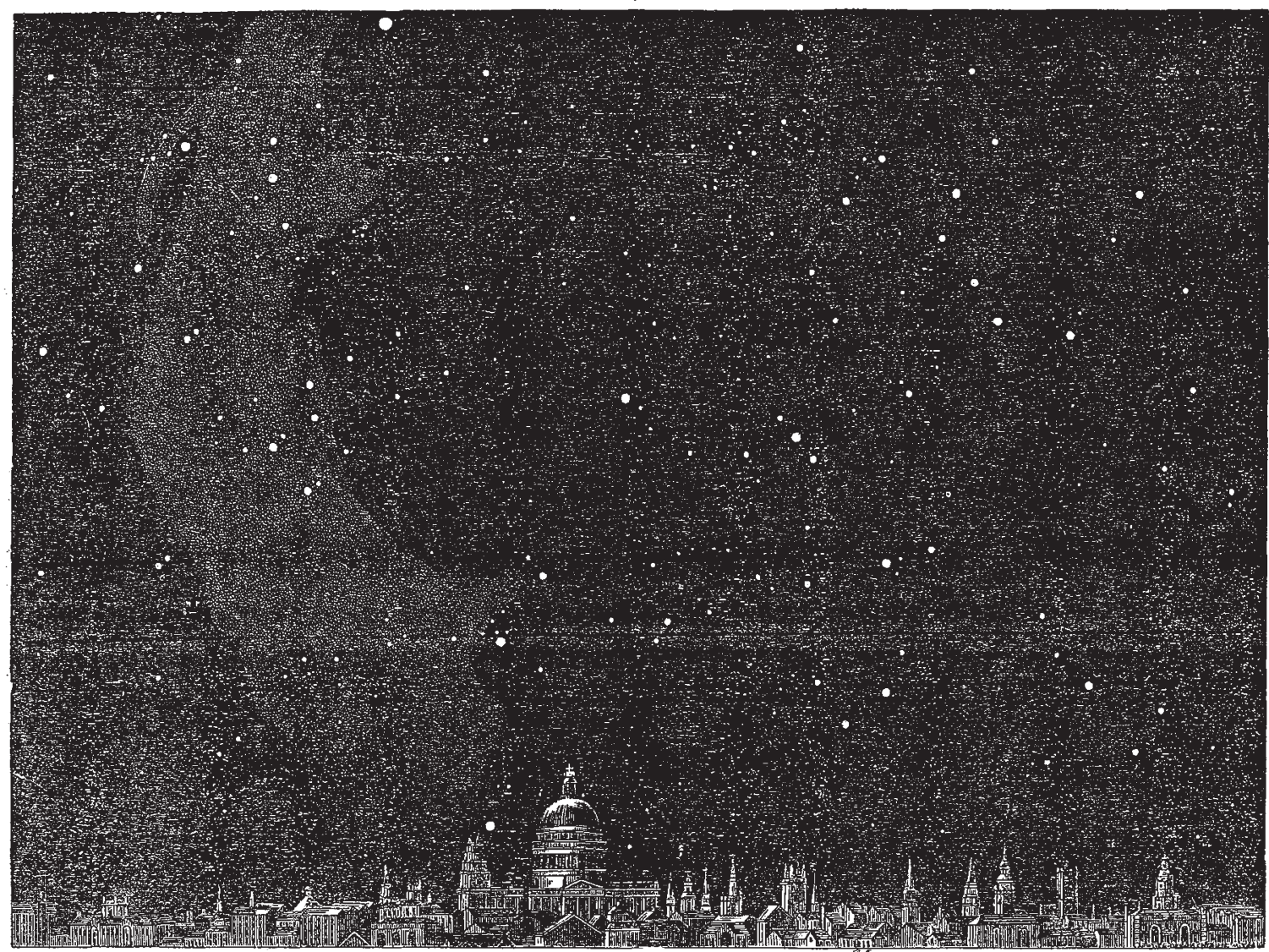

NORTHERN HEAVENS AS SEHN FROM LONDON JANUARY ${ }^{5}$ (NiD..LGHT)

stars, and of the new theory, based on that work, which has been put forward.

But enough of criticism. No; we have a little more. We think the last chapter out of place, or at all events very unhappy in its treatment, and we believe that Bishop Hall would have thought so too, and we com: mend the following extract from his Contemplations * to the attention of the $\mathrm{Re}$ ligious Tract Society:"Human learning, well improved, makes us capable of Divine. There is no knowledge whereof God is not the author: He would never have bestowed any, that should lead us away from Himself. It is an ignorant conceit, that inquiry into mature should make men atheistical." This remarkable passage contrasts strongly

* Vol ii. Look $I, p+2$ s

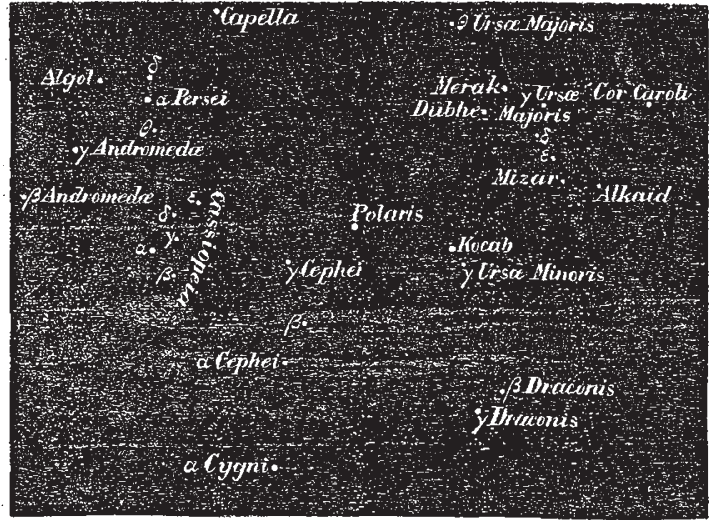

KEY-MAP

W. Herschel's forty-foot reflecting telescope, the Royal Observatory in Flamsteed's time and to-day, the great Equatorial in the Royal Observatory, and of many more interesting subjects either astronomical in themselves or connected in some way with the science. From these we have chosen an exquisite wood-cut representing a meteoric shower as seen off Cape Florida. We know no better way of giving our readers an idea of these splendid phenomena visible so rarely, than by placing this plate before them. With our ordinary experience of meteor showers, even including the brilliant one of 1866 , it is almost impossible to believe that such a splendid sight should ever have been realised, but the many published accounts which we have, leave no doubt that here also Nature had beggared description F.R.S. 


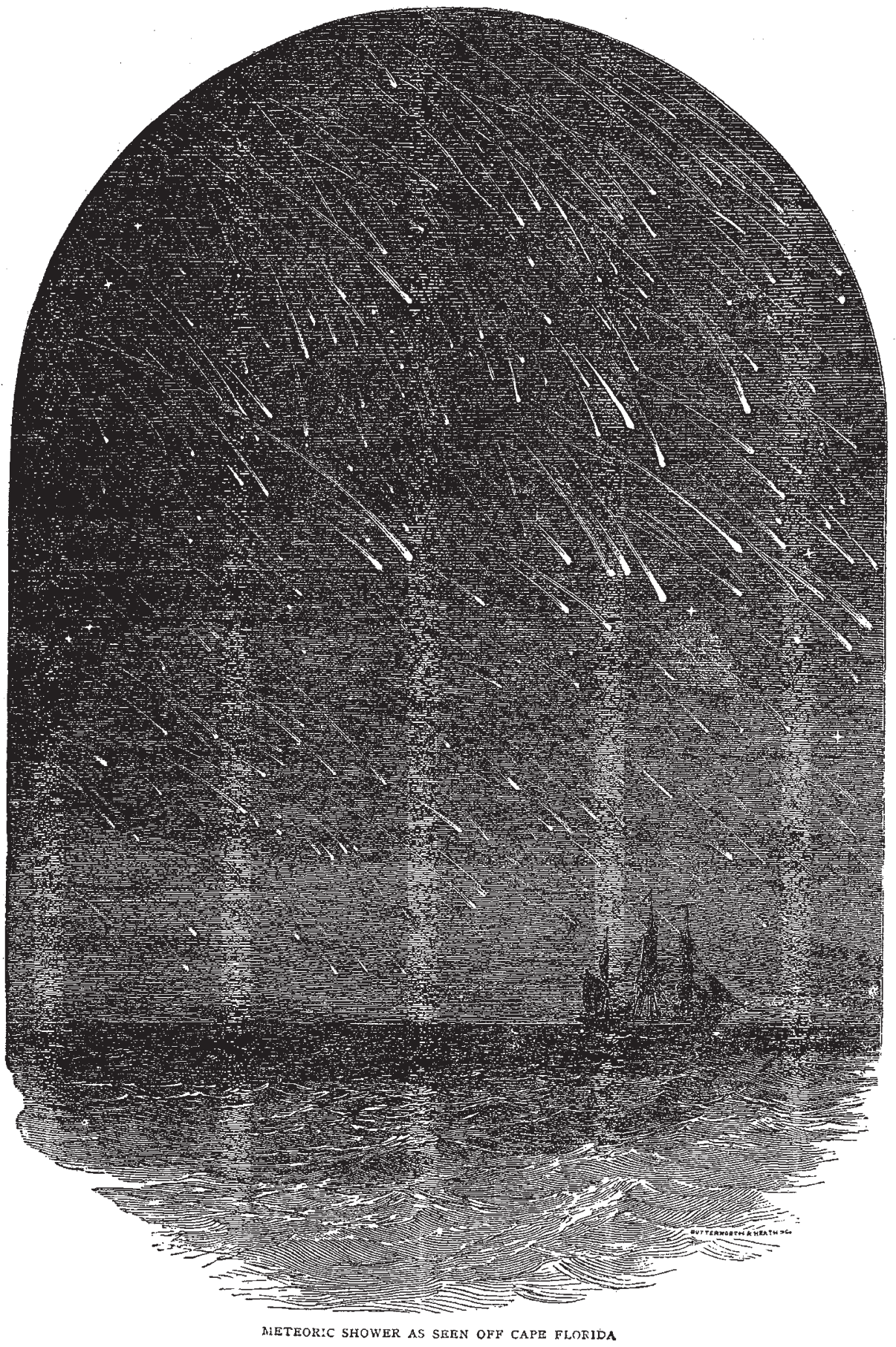

